\title{
The Agrin Gene Codes for a Family of Basal Lamina Proteins That Differ in Function and Distribution
}

\author{
Markus A. Ruegg, Karl W. K. Tsim, \\ Sharon E. Horton, Stephan Kröger, Gérard Escher, \\ Erin M. Gensch, and U. J. McMahan \\ Department of Neurobiology \\ Stanford University School of Medicine \\ Stanford, California 94305-5401
}

\section{Summary}

We isolated two cDNAs that encode isoforms of agrin, the basal lamina protein that mediates the motor neuron-induced aggregation of acetylcholine receptors on muscle fibers at the neuromuscular junction. Both proteins are the result of alternative splicing of the product of the agrin gene, but, unlike agrin, they are inactive in standard acetylcholine receptor aggregation assays. They lack one (agrin-related protein 1) or two (agrinrelated protein 2) regions in agrin that are required for its activity. Expression studies provide evidence that both proteins are present in the nervous system and muscle and that, in muscle, myofibers and Schwann cells synthesize the agrin-related proteins while the axon terminals of motor neurons are the sole source of agrin.

\section{Introduction}

The synaptic portion of a skeletal muscle fiber's basal lamina sheath is intensely stained by monoclonal antibodies (MAbs) against agrin, the protein thought to mediate the motor neuron-induced formation and maintenance of acetylcholine receptor (AChR) and acetylcholinesterase (AChE) aggregates at the neuromuscular junction. However, basal lamina at nonsynaptic sites in a variety of tissues including muscle, central nervous system (CNS), heart, and kidney, where AChRs and AChE are not known to aggregate, is also stained by these antibodies (Reist et al., 1987; Godfrey et al., 1988a, 1988b). Moreover, proteins inactive in $A C h R$ aggregation assays are immunoprecipitated from extracts of several different tissues by antiagrin MAbs (Nitkin et al., 1987; Godfrey, 1991). Such findings have led to the suggestion that anti-agrin MAbs also recognize proteins other than agrin and that these proteins differ from agrin in their function.

To identify such proteins and to determine how they are related to agrin, we screened chick cDNA libraries for homologs of CBA-1. CBA-1 encodes the C-terminal half of chick agrin, which contains the active region of agrin characterized in tissue extracts (Tsim et al., 1992). Two cDNAs highly similar to CBA-1 were identified. Transfection experiments revealed that the proteins encoded by these cDNAs are recognized by anti-agrin antibodies, but unlike agrin, they are inactive in standard AChR aggregation assays. Because the discovery of agrin was based on its ability to cause AChRs to aggregate in cultured chick myotubes (God- frey et al., 1984; Nitkin et al., 1987) and because the two proteins we describe here lack the AChR aggregating activity, but are highly similar to agrin in structure, we refer to them simply as agrin-related proteins 1 and 2 (ARP-1 and ARP-2). The predicted amino acid sequences of the agrin-related proteins are identical to that of agrin except for the absence of a stretch of 11 amino acids in ARP-1 and stretches of the 11 and 4 amino acids in ARP-2. Transfection with chimeras demonstrated that both of these stretches of amino acids are required for agrin's AChR aggregating activity as detected in tissue extracts. Southern blot and intron-exon boundary analyses showed that both agrin-related proteins are the result of alternative splicing of the transcript of a single gene. Polymerase chain reaction (PCR) was used to examine differences in the distribution of agrin and the agrin-related proteins among CNS, nerve, and muscle. Brief accounts of portions of this study have appeared elsewhere (McMahan, 1990).

\section{Results}

\section{Cloning and Expression of ARP cDNAs}

CDNA encoding ARP-1 was isolated by screening an embryonic day 13 (E13) chick brain library (Ranscht, 1988) with cDNA OL4, which codes for an agrin homolog in marine ray (M. A. Smith, C. Magill-Solc, F. Rupp, Y.-M. M. Tao, J. W. Schilling, P. Snow, and U. J. McMahan, submitted). CDNA encoding ARP-2 was isolated by using CBA-1, the CDNA that encodes the active part of chick agrin (Tsim et al., 1992) to screen an E13 chick muscle library. Based on Northern blot analysis of brain and muscle mRNA and the complete cDNA sequence for chick agrin-like protein (Tsim et al., 1992), CBA-1, ARP-1 $1_{C D N A}$, and ARP-2 ${ }_{C D N A}$ are incomplete, but they encompass about $50 \%$ of their corresponding mRNAs. All three cDNAs have a poly $(A)$ tail; thus each codes for the $C$-terminal half of its protein. The nucleotide sequences of ARP- $1_{\mathrm{CDNA}}$ and $A R P-2_{\mathrm{CDNA}}$ are identical to that of CBA-1 except for a 33 bp stretch in CBA-1 (region $B$ ) that is absent from $A R P-1_{C D N A}$ and a $12 \mathrm{bp}$ stretch (region $A$ ) as well as region $B$ in CBA-1 that are absent from $A R P-2_{C D N A}$ (Figure 1). Regions $A$ and $B$ are near the 3 ' end of the coding region of CBA-1. The 5 ' end of ARP- $1_{\text {CDNA }}$ is shorter than CBA- 1 by $155 \mathrm{bp}$, whereas the 5 ' end of $A R P-2_{C D N A}$ is shorter than CBA-1 by 429 bp.

When constructs of CBA-1 are transfected into cultured COS-7 cells, the cells secrete a protein that induces cultured chick myotubes to form AChR aggregates indistinguishable from those induced by agrin purified from the electric organ of Torpedo californica (Tsim et al., 1992). However, when COS-7 cells were transfected with constructs of ARP- $1_{\mathrm{CDNA}}$ or ARP- $2_{\mathrm{CDNA}}$, the cells in each case secreted proteins inactive in AChR aggregation assays (Figure 2; Figure 3). The pro- 

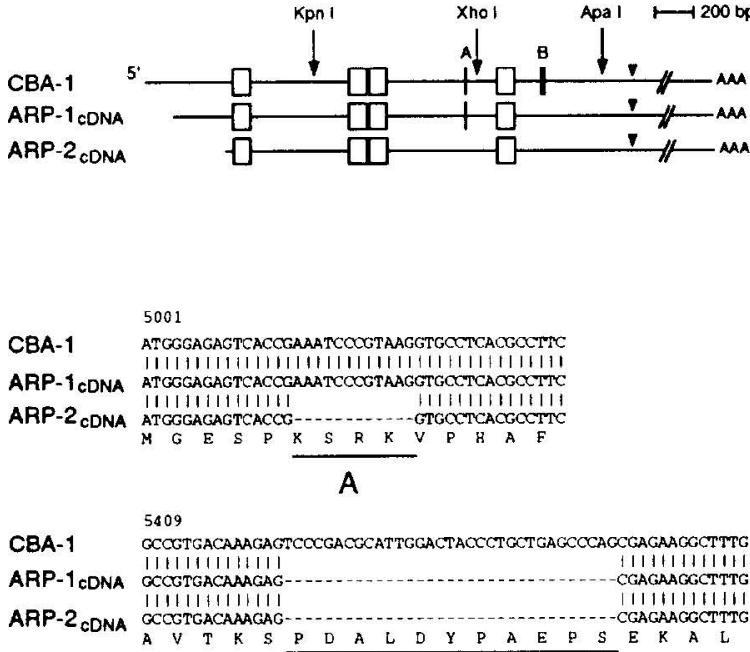

B

Figure 1. Comparison of Agrin cDNA (CBA-1) with the CDNAs Encoding ARP-1 and ARP-2

The upper diagram shows the alignment of the three cDNAs and the positions of regions A and B. ECF-like domains (boxes) and the termination codon (arrowhead) serve as points of reference. Arrows mark cleavage sites of restriction endonucleases used for chimera constructions in Figure 3. The cDNAs differ in length and in the presence of regions $A$ and $B$.

The lower portion of the figure depicts the nucleotide and deduced amino acid sequences of the three cDNAs in regions $A$ and $B$. Nucleotides are numbered according to their position in the full-length CDNA encoding chick agrin (Tsim et al., 1992). Amino acids encoded by regions $A$ and $B$ are underlined.

teins were inactive even at concentrations more than an order of magnitude greater than the concentration of CBA-1 protein required for detectable levels of activity (data not shown). Nonetheless, the protein secreted from the transfected COS-7 cells in all cases was recognized by anti-agrin MAb $5 \mathrm{~B} 1$ (see below), which was raised against Torpedo agrin and has been shown to stain the synaptic basal lamina at neuromuscular junctions in chick (Reist et al., 1987).

\section{Expression of Chimeras}

To learn whether the lack of activity in the conditioned medium of COS-7 cells transfected with cDNAs encoding agrin-related proteins was due to the absence of the 4 and/or 11 amino acid stretches near the C-terminus or the different length of the proteins at their $\mathrm{N}$-termini, we generated a set of chimeras by exchanging restriction fragments between $\mathrm{CBA}-1$ and the two other cDNAs. The chimeric constructs were transfected into COS-7 cells, and the conditioned medium was tested after 2 days for its ability to induce AChR aggregation on cultured chick myotubes under the standard conditions for assaying agrin's activity (Godfrey et al., 1984; Wallace, 1986). The exchange of the Kpnl fragment (Figure 1) between CBA-1 and ARP$2_{C D N A}$, the shorter of the two agrin-related CDNAs, resulted in two chimeric DNAs. One having the same 5 end as CBA-1 but lacking regions $A$ and $B$ encoded an
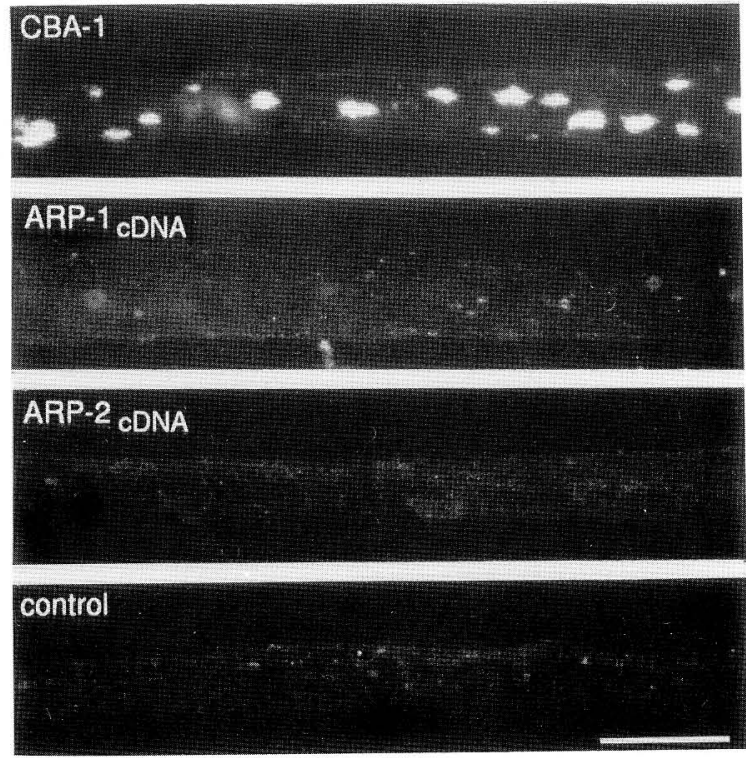

Figure 2. Proteins Encoded by ARP- $1_{\mathrm{CDNA}}$ and ARP-2, ${ }_{\mathrm{DNA}}$ Are InaCtive in AChR Aggregation Assays

Chick myotube cultures were treated overnight with equal amounts of conditioned medium from COS-7 cells transfected with expression constructs of $C D N A$ s encoding either chick agrin (CBA-1), ARP-1, ARP-2, or the expression vector pJEF14 alone (control). AChR aggregates are labeled with rhodamine-conjugated $\alpha$-bungarotoxin. Bar, $30 \mu \mathrm{m}$.

inactive protein; the other having the same 5 end as ARP- $2_{C D N A}$ but having regions $A$ and $B$ encoded an active protein (Figure 3 , top). We concluded from this that the lack of activity in the agrin-related proteins is due to the absence of the 4 and/or 11 amino acid stretches and not to the difference in length at their $\mathrm{N}$-termini.

To determine whether the insertion of region $A$ or $B$ alone would be sufficient to activate the agrin-related proteins, we constructed DNA chimeras that contained only one or both of these regions. Only conditioned medium from COS-7 cells that were transfected with DNA constructs carrying both regions $A$ and $B$ were active in AChR aggregation assays (Figure 3, top). As shown in Figure 3, the proteins encoded by all the DNA constructs were immunoprecipitated from conditioned medium by anti-agrin MAb 5B1. To determine whether each of the constructs generated the same amount of secreted agrin-like protein, we measured the amount of protein that could be immunoprecipitated in conditioned medium by MAb 5B1. Within a group of DNA constructs that had identical 5 ' ends, the amount of agrin-like protein detected in the conditioned media did not differ significantly from one to another, as determined by measuring the intensity of the major protein bands in fluorograms (Figure 3, bottom) as well as by counting the incorporated radioactivity of the bands in a scintillation counter (data not shown). Thus the absence of regions $A$ and/or $B$ in the chimeras did not affect the synthesis 


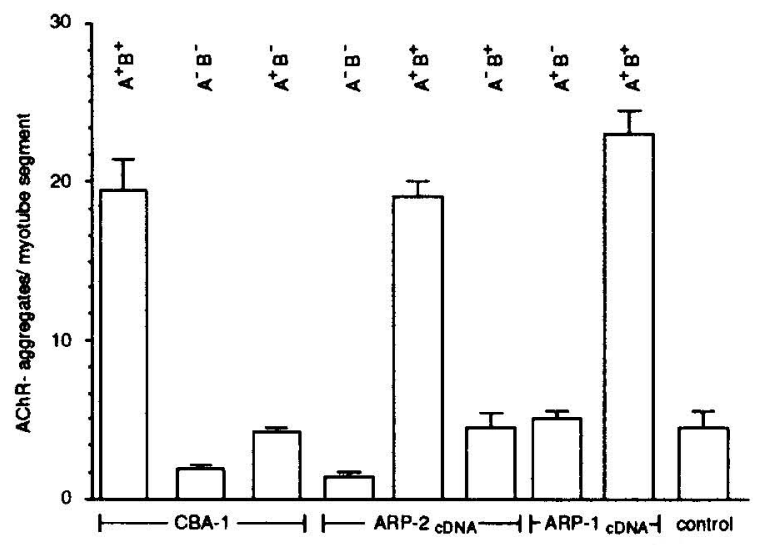

$200-$

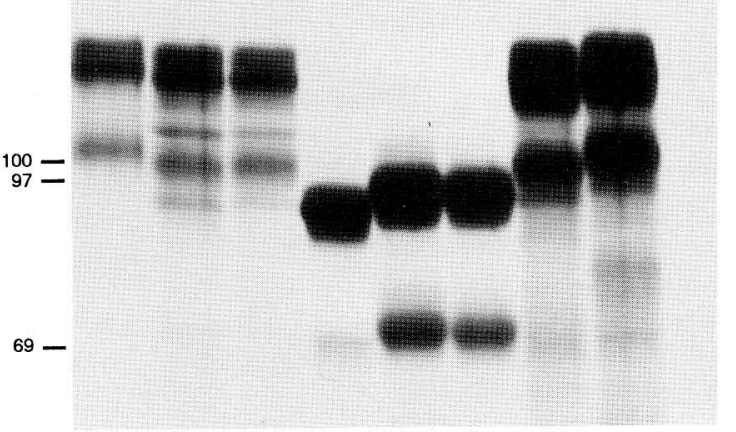

Figure 3. Regions A and B Are Required for Agrin's AChR Aggregating Activity

Top: AChR aggregating activity of conditioned medium from COS-7 cells transfected with expression constructs of CBA-1, ARP-1 $1_{C D N A}, A R P-2_{\triangle D N A}$ (see Figure 1), and chimeras having or lacking regions $A$ and $B$, as assayed in chick myotube cultures. Control medium was from COS-7 cells transfected with the expression vector alone. AChR aggregates/myotube segment are expressed as mean \pm SEM from triplicate cultures. Only conditioned media from COS-7 cells that were transfected with DNA constructs containing both regions $A$ and $B\left(A^{+} B^{+}\right)$were biologically active.

Bottom: Amount of secreted agrin-like protein generated by each of the constructs in the experiment shown above. Metabolically labeled proteins secreted by COS-7 cells transfected with each chimera were immunoprecipitated from conditioned medium with anti-agrin MAb 5B1 as described in Experimental Procedures, separated by SDS-polyacrylamide gel electrophoresis, and visualized by fluorography. Conditioned medium from COS-7 cells transfected with each of the three CDNAs and their chimeras contained similar amounts of antigenic protein, indicating that the synthesis and secretion of the agrin-like proteins were not affected by the presence or absence of regions $A$ and B. Molecular mass markers are indicated in kilodaltons.

and secretion of the recombinant proteins in COS-7 cells, but rather the ability of the protein to induce the aggregation of AChRs on chick myotubes. Only the proteins active in the $A C h R$ aggregation assay also induced myotubes to form aggregates of AChE (data not shown) as does agrin either purified from Torpedo electric organ or secreted by COS-7 cells transfected with CBA-1 (Wallace et al., 1985; Tsim et al., 1992).
This indicates that the aggregation of both AChRs and $\mathrm{AChE}$ is mediated by the same region in the agrin protein.

\section{Alternative Splicing}

The structure of the cDNAs encoding agrin-related proteins suggested to us that the agrin isoforms might be the result of alternative splicing. To test this hypothesis, we first performed Southern blot analysis of chick genomic DNA. A probe common to all three cDNAs (nucleotides 3218-4217; Tsim et al., 1992) was hybridized to genomic DNA that was digested with different restriction endonucleases. As shown in Figure $4 A$, the probe hybridized to only a single restriction fragment, except for fragments generated by BamHI. The two fragments labeled in this case are due to a BamHI restriction site in the probe. Reprobing the blots with a cDNA clone from the 5 ' end of full-length chick agrin (nucleotides 1-1114; Tsim et al., 1992) also revealed single bands (data not shown). These findings indicate that agrin and agrin-related proteins are encoded by a single gene and that they are the result of posttranscriptional modification. We extended this observation by amplifying a portion of the agrin gene that included regions $A$ and $B$ by PCR technique. The PCR products were then sequenced using oligonucleotides deduced from the nucleotide sequence of CBA-1. The structure of the chick agrin gene that spans regions $A$ and $B$ is shown schematically in Figure $4 B$. This region of the gene consists of four exons that are flanked by intron sequences which conform to empirical rules for splice junctions (e.g., Padgett et al., 1986). The first exon, 12 bp long, corresponds to region $A$ and is followed by an exon that encodes the entire fourth epidermal growth factor (EGF)-like domain of agrin. The third exon is $87 \mathrm{bp}$ in length, and the fourth exon corresponds to the 33 bp region $B$. Thus, regions $A$ and $B$ are encoded by separate exons, and they are alternatively spliced into mRNA derived from the agrin gene (Figure 4B).

Theoretically, the two alternative splicing sites could generate four different species of mature transcripts. Agrin $\left(\mathrm{A}^{+} \mathrm{B}^{+}\right)$, ARP-1 $\left(\mathrm{A}^{+} \mathrm{B}^{-}\right)$, and ARP-2 $\left(\mathrm{A}^{-} \mathrm{B}^{-}\right)$ account for three of these species. We searched for the fourth transcript $\left(A^{-} B^{+}\right)$in different parts of the CNS (the only tissue examined that contained mRNA having region $\mathrm{B}$; see below) by performing the following experiments: Reverse transcribed mRNA was subjected to a first round of amplification using one primer (1s) located upstream of region $A$ and one primer (2a) inside of region B (see Figure $4 B$ for location of primers). To determine whether the amplified DNA contained two different populations $\left(\mathrm{A}^{+} \mathrm{B}^{+}\right.$and $\left.\mathrm{A}^{-} \mathrm{B}^{+}\right)$, we subjected the PCR products to a second round of amplification using the nested primers $2 \mathrm{~s}$ and 1a that flank region $A$. As shown in Figure $4 C$, we found only products that carry region $A$, indicating that all detectable transcripts having region $B$ also had region $A$. Thus alternative splicing of the exons encoding regions $A$ and $B$ in the chick CNS results in detect- 
A

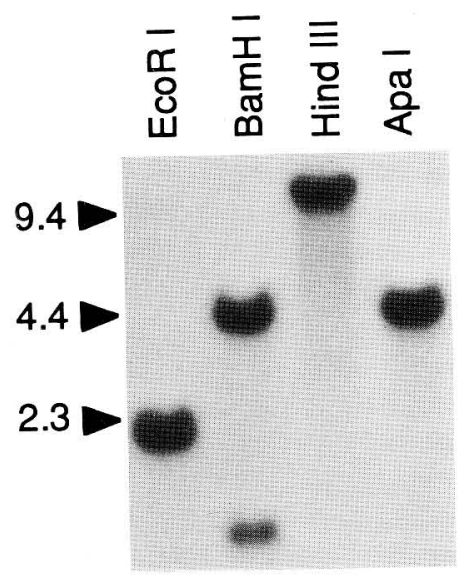

C

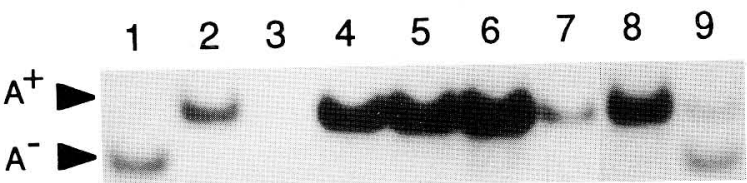

$\mathrm{B}$
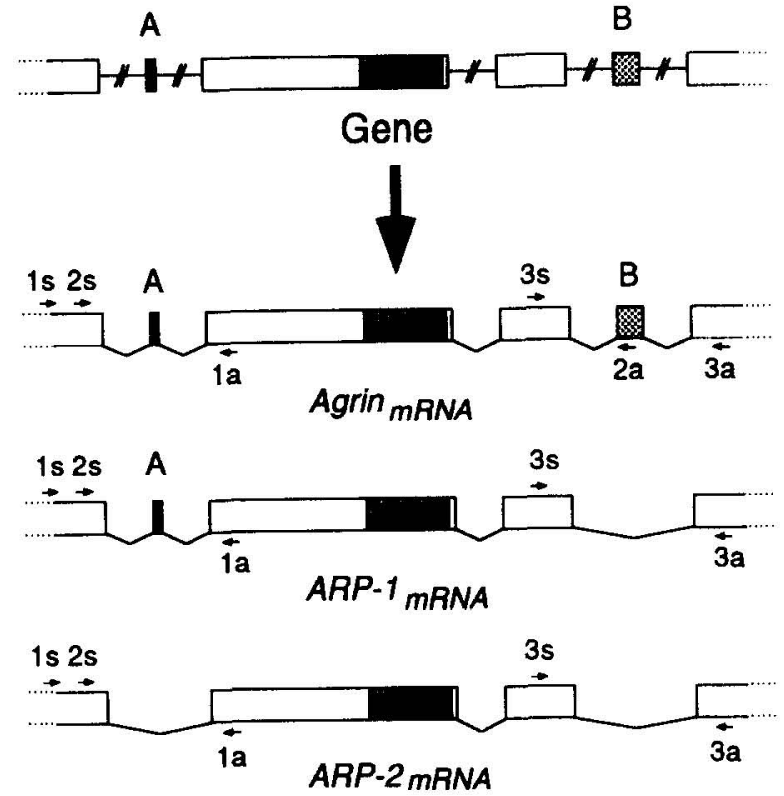

$100 \mathrm{bp}$

Figure 4. Agrin, ARP-1, and ARP-2 Are Generated by Alternative Splicing of a Single Gene Product

(A) Southern blot analysis of genomic DNA using a probe common to agrin and agrin-related proteins reveals a single gene. Restriction endonucleases used to digest genomic DNA are shown at the top of each lane. Molecular size markers are in kilobases. The probe hybridized to a single band in each lane, except for the second lane. The double band in this lane is due to a BamHI restriction site in the probe.

(B) Exon-intron organization of the portion of the chick agrin gene that spans regions A and B indicates that the two regions are alternatively spliced to form different transcripts. The fourth ECF-like domain (shaded segment) and the location of primers (arrows) used in the PCR experiments that follow are shown.

(C) Transcripts that contained region B always contained region A in the CNS. Autoradiogram of PCR products obtained using primers 2s and 1a. ARP- $2_{C D N A}$, which lacks region $A$ (lane 1), and $A R P-1_{\mathrm{CDNA}}$, which has region $A$ (lane 2), were used as templates to reveal the position of PCR products having and lacking region $A$. In lanes 4-7, the templates were the PCR products obtained from a first round of amplification using cDNA from reverse transcribed mRNA from different parts of the chick CNS and oligonucleotides $1 \mathrm{~s}$ and $2 \mathrm{a}$, which primed only those cDNAs that contained region B. mRNA was isolated from E13 brain (lane 4), E13 spinal cord (lane 5), and cell fractions of E6 spinal cord that were either enriched in motor neurons (lane 6) or non-motor neurons (lane 7) as described by Tsim et al. (1992). As positive controls, we used as a template in the first amplification a mixture of CBA-1, ARP-1 ${ }_{\mathrm{CINA}}$, and ARP- $2_{\mathrm{C} I N A}$ (lane 8), or the same mixture of CDNAs plus a chimeric construct that lacked region A but carried region B (lane 9). As a negative control, the reverse transcription reaction was carried out without adding $\mathrm{mRNA}$ (lane 3). All PCR products obtained from CNS mRNA have region $A$, indicating that the CNS contains few, if any, transcripts lacking exon $A$ but having exon $B\left(A^{-} B^{+}\right)$. Accordingly, most if not all transcripts that contain region $B$ also contain region $A$, which is characteristic of agrin.

able levels of expression of only three of the four possible species of transcripts: those encoding agrin $\left(A^{+} B^{+}\right)$, ARP-1 $\left(A^{+} B^{-}\right)$, and ARP-2 $\left(A^{-} B^{-}\right)$(Figure $\left.4 B^{3}\right)$. The presence of $m R N A$ having region $B$ in the $C N S$ is indicative of agrin transcripts, whereas the absence of region $A$ is indicative of mRNA encoding ARP-2.

\section{Differential Tissue Distribution}

We used PCR techniques with oligonucleotides flanking region $B$, which distinguishes agrin from the two agrin-related proteins, to determine whether transcripts with this insert could be found in peripheral nerve and muscle as in the CNS (Tsim et al., 1992). Although such transcripts were clearly present in preparations of embryonic chick brains, they could not be detected in either embryonic sciatic nerve or muscles (Figure 5, lower panel). Thus agrin transcripts either are not present or are below detectable levels in nerve and muscle.

Using the same approach, we searched CNS, nerve, and muscle tissues for transcripts either having $A$ but lacking B, or lacking both A and B characteristic of the transcripts encoding ARP-1 and ARP-2. As illustrated in Figure 5, both were present in the CNS. Transcripts encoding ARP-1 were more abundant than those for ARP-2 and agrin. We detected transcripts for only ARP-2 in sciatic nerve. There were transcripts for ARP-2 in all muscles examined from E16 to posthatch day 7 and in 5 day myotube cultures, which are routinely used for our activity assay. Transcripts for ARP-1 were found in hindlimb muscles and in the myotube cultures (made from chick hindlimb muscles) but were at least 50 times less abundant than those for ARP-2, as determined by densitometry of the autoradiograms. 

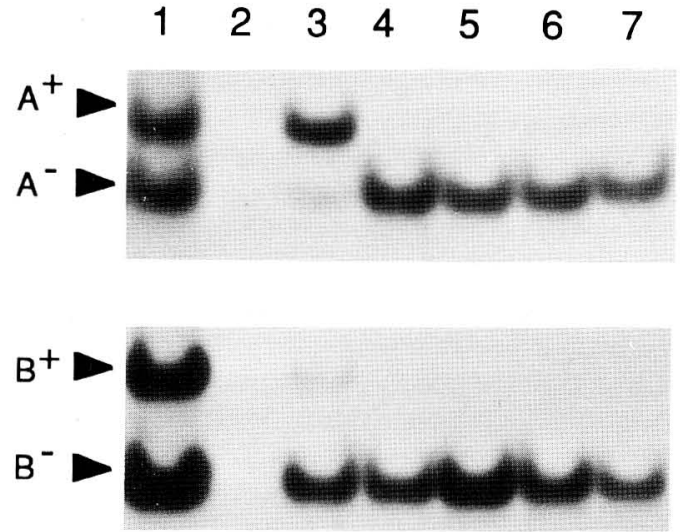

Figure 5. The Relative Abundance of Transcripts for Agrin and Agrin-Related Proteins Differs among CNS, Nerve, and Muscle Autoradiogram of PCR products obtained by using CDNA generated from mRNA of E13 brain (lane 3), E16 pectoral muscle (lane 4), posthatch day 7 hindlimb muscle (lane 5), myotubes cultured for 5 days (lane 6), and E17 sciatic nerve (lane 7). As a negative control, samples with no RNA added were subjected to PCR (lane 2). The positions of $P C R$ products lacking inserts $A$ or $B$ and those having these inserts were revealed by using a mixture of CBA-1 and $A R P-2$ CDA (lane 1). Oligonucleotides flanking insert $A$ (2s and 1a; Figure $4 B$ ) were used as primers in the upper panel; those flanking insert $B$ ( 3 s and 3a; Figure $4 B$ ) were used as primers in the lower panel. From the relative amounts of $P C R$ products containing or lacking inserts $A$ and $B$, it is apparent that transcripts encoding ARP-1 $\left(A^{+} B^{-}\right), A R P-2\left(A^{-} B^{-}\right)$, as well as agrin $\left(A^{+} B^{+}\right)$ are present in the brain; transcripts for $A R P-1$ are most abundant. $P C R$ product containing insert $B$ was not detected in muscle and sciatic nerve (even after exposure times 20 -fold longer than that used for this figure), indicating that these tissues do not contain agrin transcripts. However, PCR product lacking regions $A$ and $B$ was detected. Thus sciatic nerve and muscle contain transcripts that encode ARP-2. Prolonged exposure of the autoradiogram also revealed $P C R$ product containing region $A$ in certain muscles (see Results).

Altogether, the results indicate that among CNS, nerve, and muscle tissues, agrin transcripts are present only in the CNS, and that while agrin-related proteins are present in all three tissues, their relative abundance varies between the tissues.

\section{Discussion}

We demonstrate that chick nervous tissue and muscle contain two proteins that are highly similar to agrin in their structure but lack the AChR/AChE aggregating activity characteristic of agrin. Southern blot analysis of chick genomic DNA using probes common to all three cDNAs revealed a single band, and analysis of the intron-exon boundaries showed that the amino acid stretches that are absent from the two proteins are encoded by separate exons. Thus, the two proteins are members of a family of functionally different proteins generated from the agrin gene by alternative splicing of a common precursor mRNA.

The cDNAs we used to identify and characterize the two agrin-related proteins code for the $\mathrm{C}$-terminal half of the proteins. We did not seek to use full-length cDNA for the following reasons:

- Because of their large size, $\sim 8 \mathrm{~kb}$ (Tsim et al., 1992), full-length cDNAs for the agrin-related proteins, as for agrin in any species, have not been cloned. Indeed, to generate hypotheses as to how agrin might interact with cellular and extracellular components of the synapse, sequence for full-length agrin-like protein in chick (Tsim et al., 1992) and ARP-like protein in rat (referred to as agrin; Rupp et al., 1991; Campanelli et al., 1991) have been assembled by piecing together cDNAs from primer extension libraries and linking them to cDNA for the C-terminal half of agrin and an agrin-related protein. It is not known, however, whether the primer extension cDNAs used for either of the assemblies code for agrin or agrin-related proteins or both. The importance of using the exact sequence for a specific protein in expression experiments is illustrated by our finding here that the presence or absence of a stretch of only a few amino acids near the C-terminus of agrin determines the presence or absence of activity.

-It is not known to date whether, in vivo, full-length agrin and agrin-related proteins are secreted, and if so, whether they are active. Native agrin has been best characterized in basal lamina extracts of the electric organ of the ray $\mathrm{T}$. californica. The extracts contain two forms of agrin, 150 and $95 \mathrm{kd}$, both of which have AChR/AChE aggregating activity (Nitkin et al., 1987). Both proteins are likely to be derived from a larger protein that is proteolytically cleaved either during tissue extraction or during in situ posttranslational modification; the $95 \mathrm{kd}$ form is located in the C-terminal half of the large protein (Smith et al., submitted; Tsim et al., 1992). Indeed, when the C-terminal half of chick agrin, which is encoded by CBA- 1 and encompasses a region homologous to the $95 \mathrm{kd}$ form of ray agrin, is transfected into COS-7 cells, the cells induce cultured myotubes to form AChR/AChE aggregates that are indistinguishable from those induced by purified ray agrin both in their appearance and in the manner of their formation (Tsim et al., 1992). Accordingly, by using for this study a cDNA for each protein that was from a single clone and encoded the C-terminal half of the protein, we could be certain that the entire sequence of the CDNA was represented in a native transcript. This strategy also ensured that if the CDNA coded for a protein lacking AChR/AChE aggregating activity, the absence of activity was due to alterations at or near the active region of agrin as characterized in electric organ extracts.

We found that the C-terminal halves of the agrinrelated proteins predicted by the CDNAs were identical to that of agrin except for the absence of an 11 amino acid stretch in ARP-1 and the 11 and 4 amino acid stretches in ARP-2 and that both domains are required for agrin's activity. This raises the possibility that these domains encompass all or part of the sequence that interacts with agrin receptors (Nitkin et al., 1987; Wallace et al., 1991; Nastuk et al., 1991) in 
muscle fibers. Previous studies have provided strong evidence that the $A C h R / A C h E$ aggregating effect of ray agrin (from electric organ extracts) is indistinguishable from that of chick agrin (in medium conditioned by COS-7 cells transfected with CBA-1; Tsim et al., 1992). Comparison of the protein sequence predicted by the cDNAs encoding agrin-like proteins in ray (Smith et al., submitted) and rat (Rupp et al., 1991) show that the 4 amino acids of region $A$ are identical in all three species. However, only 6 of the amino acids in the 11 amino acid stretch in chick agrin (deduced from the cDNA sequence) are identical to those in the 11 amino acid stretch in ray agrin (deduced from the sequence of the ray PCR product) (Tsim et al., 1992). Accordingly, if the $\mathbf{1 1}$ amino acid stretch includes all or part of the active domain of agrin, only those amino acids conserved across species might be expected to interact directly with the muscle fiber's agrin receptors. An alternate function for the 4 and 11 amino acid stretches is that none of the residues in the stretches directly interact with the muscle fiber, but rather, they help to confer on the protein a shape that exposes other residues that do. The 4 and 11 amino acid segments flank each side of agrin's fourth EGF-like domain. Such domains in other proteins are known to be involved in cell-cell interactions (Fehon et al., 1990; Rebay et al., 1991), raising the question of whether this domain bears part or all of the active site in agrin. We note that the synthetic 11 amino acid peptide by itself neither induces AChR aggregation nor inhibits Torpedo agrin's AChR aggregating activity in myotube cultures (unpublished data).

Because agrin-like transcripts having the $\mathbf{1 1}$ amino acid stretch characteristic of chick agrin have been identified by PCR in ray (Tsim et al., 1992), it is likely that the stretch is a component of agrin in all vertebrate species. cDNAs isolated thus far from ray (Smith et al., submitted) and rat (Rupp et al., 1991) libraries code for proteins that have the 4 amino acid but not the 11 amino acid stretch, indicating that ARP-1 is also conserved across species. According to the results we present here, one might predict that both ray and rat cDNAs would code for inactive proteins. Indeed, we found that when we transfected COS-7 cells with the ray $C D N A$, which, like all of the CDNAs used in this study, was from a single clone and coded for the C-terminal half of its protein, the cells secreted protein recognized by an anti-agrin $M A b$ and inactive in our AChR aggregation assays (unpublished data). The C-terminal half of rat ARP- $1_{\text {CDNA }}$ has been transfected into both COS-7 and $\mathrm{CHO}$ cells by Campanelli et al. (1991). However, it was linked to cDNAs for agrin and/ or agrin-related proteins isolated from a primer extension library to generate a full-length ARP-like protein. When the transfected cells were cocultured with rat myotubes, AChR aggregates formed at some of the sites where the transfected cells contacted the myotubes. One explanation for the activity of the fulllength rat ARP-like protein is that it may have some $A C h R$ aggregating activity in, or generated by, its
$\mathrm{N}$-terminal half. It will be of interest to learn whether or not any transcript of the agrin family encodes a protein having activity dependent on the presence of its N-terminal half and, if so, whether the mechanism of action is similar to that of the activity we have demonstrated in the C-terminal half. Several agents, including ARIA (Usdin and Fischbach, 1986), calcitonin gene-related peptide (New and Mudge, 1986), sciatin (Oh and Markelonis, 1982), laminin (Vogel et al., 1983), ascorbic acid (Knaack et al., 1986), and Latex beads (Peng et al., 1981), induce low levels of AChR aggregation on cultured myotubes, apparently through mechanisms other than those described for agrin in tissue extracts (see Nitkin et al., 1987, for discussion).

Alternative splicing may give rise to forms of agrin and the agrin-related proteins other than the ones we describe. An additional site where alternative splicing might occur has been noted in studies on rat ARP- $1_{C D N A}$ (Rupp et al., 1991). We found that this site is near the 5 ' end of both the chick agrin cDNA CBA-1 (nucleotide 3517-3544; Tsim et al., 1992) and the chick cDNA encoding ARP-1, but it is not encompassed in the sequence of the chick CDNA encoding ARP-2. Because the insertion of regions $A$ and $B$, which encode the 4 and 11 amino acid stretches, into ARP- $2_{\text {CDNA }}$ is sufficient to generate an active protein, any region that might be inserted at the potential splicing site identified in the rat CDNA is not required for agrin's AChR/ AChE aggregating activity. Our results predict that if there are several members of the family of proteins derived from the agrin gene other than the ones we describe, they must have inserts at the sites of the 4 and the 11 amino acid stretches to have the AChR/ AChE aggregating activity typical of agrin, as characterized in electric organ extracts.

Immunohistochemical studies (Reist et al., 1987; Magill-Solc and McMahan, 1988; Godfrey et al., 1988b; Fallon and Gelfman, 1989) on muscles and nerves in chick embryos have demonstrated that, in addition to staining the synaptic portion of the muscle fiber's basal lamina, antibodies directed against agrin stain the basal lamina of the Schwann cells that cap the axon terminal at the neuromuscular junction and ensheath the preterminal axons within nerves. The basal lamina of muscle fibers stains more or less uniformly prior to innervation (Godfrey et al., 1988b), and such staining persists in the embryo even if innervation is prevented (Fallon and Gelfman, 1989). In adult chicks, antibodies to agrin stain Schwann cell and synaptic basal lamina, but extrajunctional staining of muscles is restricted to tonic fibers. These findings lead to the conclusion that proteins related to agrin are synthesized by Schwann cells and muscle fibers. Several lines of evidence (Burden et al., 1979; McMahan and Slater, 1984; Magill-Solc and McMahan, 1988; Reist et al., 1992; Tsim et al., 1992) indicate that at least some of the anti-agrin staining of the synaptic basal lamina is due to the presence of agrin produced by motor neurons. The fact that we find mRNA for only ARP-2 in peripheral nerve indicates that the protein stained 
by anti-agrin antibodies in Schwann cell basal lamina both in peripheral nerve and at the neuromuscular junction is ARP-2. The fact that we find in embryonic and posthatch muscle mRNAs for ARP-2 and, in much less abundance, ARP-1 indicates that the protein stained by anti-agrin antibodies in muscle basal lamina outside the synaptic region is either one or both of the agrin-related proteins. One or both agrin-related proteins may also be present in the synaptic basal lamina along with agrin. Our failure to detect any agrin transcripts in peripheral nerve and muscle makes it highly likely, however, that the only agrin at the neuromuscular junction is provided by the motor axon terminal. Consistent with this conclusion are PCR experiments that revealed transcripts for only agrin-related proteins in the electric organ of the ray (unpublished data), which is a homolog of muscle but is much richer in innervation and which yields relatively large amounts of agrin.

Immunohistochemical studies on the CNS of adult rays and frogs and of both embryonic and posthatch chicks (Magill-Solc and McMahan, 1988) have demonstrated that, in addition to staining the cell bodies of motor neurons, anti-agrin MAbs intensely stain the basal lamina that occupies the narrow space between the capillary endothelium and astrocyte end feet throughout gray and white matter. The antibodies also stain the surface of the CNS that is lined by basal lamina-coating astrocyte processes. Our finding that mRNAs for ARP-1 and ARP-2 are expressed by nonneural cells in peripheral nerve and muscle raises the possibility that they are expressed by nonneural cells in the CNS and account for the staining of basal lamina within and on the surface of the brain. Indeed, that nonneural cells contain mRNA for agrin-like protein has been demonstrated by in situ hybridizations using probes common to agrin and agrin-related proteins; the white matter in spinal cord, which contains the mRNA of capillary and glial cells, including astrocytes, but not of neurons is distinctly labeled (Smith et al., submitted).

In addition to staining nonsynaptic basal lamina in skeletal muscle, nerve, and CNS tissues, anti-agrin MAbs stain the glomerular basal lamina in the chick kidney (Godfrey, 1991), the myofiber basal lamina in cardiac muscle, the basal lamina of smooth muscle cells, and tunica intima in certain blood vessels (Reist et al., 1987; Godfrey et al., 1988a). Neither AChRs nor $A C h E$ is aggregated in the plasma membranes of the cells with which these basal laminae are associated. Moreover, proteins immunoprecipitated by anti-agrin antibodies from adult chick kidney, embryonic heart, and embryonic skeletal muscle have little or no activity in AChR aggregation assays (Godfrey, 1991). Based on our findings, we propose that the lack of correspondence between the distribution of proteins recognized by anti-agrin MAbs and the distribution of AChR aggregating activity is due to the differential distribution of members of the family of basal lamina proteins that are encoded by the agrin gene and differ from agrin in function. The agrin-related proteins might simply be structural proteins necessary for the assembly and maintenance of the basal lamina in which they reside. Alternatively, they could be involved in the aggregation of specific proteins in the plasma membrane of the cells this basal lamina abuts (Magill-Solc and McMahan, 1988). Agrin-related proteins in the CNS might be expressed by neurons as well as nonneural cells and, as suggested for agrin (McMahan, 1990), serve to induce the aggregation of neurotransmitter receptors at neuron-to-neuron synapses. The difference in activity between agrin and the two related proteins described here is the result of exceedingly small differences in the primary protein structure. Identification of such structural differences will be useful for experiments aimed at understanding the function, regulation, and distribution of members of this novel family of proteins.

\section{Experimental Procedures}

Isolation and Analysis of CDNAs

ARP-1 $1_{\text {CDNA }}$ was isolated from an E13 chick brain library as described in Tsim et al. (1992). ARP-2 $2_{\text {CNA }}$ was isolated from an oligo(dT)-primed E13 chick muscle $\lambda$ gt10 library (courtesy of W. R. Randall). About $3 \times 10^{5}$ recombinants were screened according to Sambrook et al. (1989) with random-primed, 32P. labeled CBA-1 (Feinberg and Vogelstein, 1983): Replica filters were incubated overnight at $42^{\circ} \mathrm{C}$ in $30 \%$ formamide, $5 \times 5 S C$, $5 \times$ Denhardt's reagent, $0.1 \%$ SDS, $0.1 \mathrm{mg} / \mathrm{ml}$ denatured salmon sperm DNA. Filters were washed three times at $65^{\circ} \mathrm{C}$ with $0.2 \times$ SSC, $0.2 \%$ SDS. This procedure yielded 8 positive clones, which were subsequently isolated. The longest clone, ARP- $2_{\text {CDNA, was }}$ chosen for further analysis. ARP- $1_{\text {CDNA }}$ and ARP-2 ${ }_{\text {CDNA }}$ were subcloned into pBluescriptll $\mathrm{KS}(+)$ (Stratagene), and their coding regions were completely sequenced by the dideoxy chain termination method (Sanger et al., 1977) using a Sequenase kit (USB). Sequencing primers were synthetic oligonucleotides deduced from CBA-1.

\section{Expression Constructs and Generation of Chimeras}

All cDNAs and chimeras were expressed in COS-7 cells by using the SR- $\alpha$-based expression vector pJEF14 (Elliott et al., 1990), modified as described in Tsim et al. (1992). All DNA constructs were subcloned into this vector using the EcoRl site in its polylinker. Orientation of the inserts was determined by restriction mapping and sequencing the $5^{\prime}$ end of the constructs. DNA used in transfection experiments was purified twice on a cesium chloride gradient (Sambrook et al., 1989). Chimeric DNAs were constructed as follows: For ARP-2 $2 D N A$ containing regions $A$ and $B$ and CBA-1 lacking these regions, constructs in pBluescript/I KS were digested with the restriction enzyme Kpnl and the corresponding DNA fragments were interchanged. For constructs of CBA-1 lacking region $B, A R P-2_{C D N A}$ having region $B$ and $A R P-1_{1 D N A}$ containing regions $A$ and $B$, all cDNAs were first subcloned into the ECoRI site of the PT7-7 cloning vector (Tabor and Richardson, 1985). Constructs were then double digested with the Xhol and Apal restriction enzymes, and the resulting Xhol-Apal fragments were interchanged between the different constructs.

\section{Activity Assays}

All expression constructs were transfected into COS-7 cells using a DEAE-dextran procedure as modified by Luthman and Magnusson (1983). After 2-3 days, conditioned media from these cultures were applied to 5-day-old triplicate cultures of chick myotubes for 14-20 hr. AChRs were labeled for $1 \mathrm{hr}$ at $37^{\circ} \mathrm{C}$ with $3 \times 10^{-8} \mathrm{M}$ rhodamine-conjugated $a$-bungarotoxin (Molecular Probes). Myotube cultures were subsequently washed 3 times with phosphate-buffered saline, fixed for $5 \mathrm{~min}$ at $-20^{\circ} \mathrm{C}$ in $95 \%$ etha- 
nol, covered by coverslips mounted with Citifluor (City University, London), and examined by fluorescence microscopy. The mean number of $A C h R$ aggregates per myotube segment (600 $\mu \mathrm{m}$ in length) was determined by counting $A C h R$ aggregates with their shortest axis $>2 \mu \mathrm{m}$ in 20 different segments in each of 3 cultures.

\section{Immunoprecipitations and Gel Electrophoresis}

The amount of specific protein secreted by the transfected COS-7 cells was determined as follows: After removing the conditioned medium to assay for AChR aggregating activity, the same COS-7 cells were pulse labeled overnight in $1 \mathrm{ml}$ of medium containing $100 \mu \mathrm{Ci}$ of $\left.{ }^{35} \mathrm{~S}\right]$ methionine (Amersham) and $1 \%$ fetal calf serum. Conditioned medium was collected, and cell debris was removed by centrifugation $(14,000 \times \mathrm{g}$ for $10 \mathrm{~min})$. The medium was brought to $150 \mathrm{mM} \mathrm{NaCl}, 5 \mathrm{mM}$ EDTA, $1 \%$ Triton $\mathrm{X}-100$, $50 \mathrm{mM}$ Tris- $\mathrm{HCl}(\mathrm{pH} 7.5)$, and $5 \mu$ lof ascites fluid containing the MAb 5B1 (Reist et al., 1987) was added. After overnight incubation at $4^{\circ} \mathrm{C}, 100 \mu$ l of a 1:1 suspension of protein A-Sepharose beads (Pharmacia) was added, and the incubation was continued for $2 \mathrm{hr}$ at room temperature. Beads were pelleted by centrifugation and washed sequentially as described in Nitkin et al. (1987). Bound antigen-antibody complexes were released by boiling for 5 min in $60 \mu$ of SDS-polyacrylamide gel electrophoresis sample buffer (3\% SDS, 5\% 2-mercaptoethanol, 15\% glycerol, $0.001 \%$ bromphenol blue in $62.5 \mathrm{mM}$ Tris $-\mathrm{HCl}[\mathrm{pH} 6.5])$. Proteins were analyzed on 7.5\% SDS-polyacrylamide gels (Laemmli, 1970), and the gels were processed for fluorography according to Bonner and Laskey (1974). The dried gels were exposed to X-ray films at $-70^{\circ} \mathrm{C}$ for various lengths of time. Fluorograms were scanned using a densitometer (LKB-Pharmacia). Results obtained from densitometry were confirmed by cutting the major bands out from the gels and counting the radioactivity incorporated in a liquid scintillation counter (Beckman). Molecular mass markers (Amersham) were ${ }^{14} \mathrm{C}$-methylated myosin (200 kd), phosphorylase (100 and $97 \mathrm{kd})$, and albumin $(69 \mathrm{kd})$. Immunoprecipitation of the antigen-depleted supernatant from COS-7 cells with $2 \mu \mathrm{l}$ of ascites containing $\mathrm{MAb} 5 \mathrm{~B} 1$ ascertained that more than $95 \%$ of the proteins was detected in the first immunoprecipitation.

\section{Southern Blot Analysis}

Ten micrograms of chick genomic DNA (Clontech) was digested to completion with the restriction enzymes indicated in Figure 4. DNA fragments were separated on a $0.8 \%$ agarose gel, transferred to nylon membranes (Hybond-N, Amersham), and probed with the ${ }^{32}$ P-labeled 5 ' EcoRI-Kpnl fragment of CBA-1 (nucleotides 3218-4217; Tsim et al., 1992), prepared by randomly primed DNA synthesis. Hybridization conditions were as described for the isolation of cDNAs. Blots were washed first in $2 \times$ SSC, $0.1 \%$ SDS for $30 \mathrm{~min}$ at room temperature and then twice in $0.1 \times \mathrm{SSC}$, $0.1 \%$ SDS for $30 \mathrm{~min}$, each at $65^{\circ} \mathrm{C}$. Filters were exposed to $\mathrm{X}$-ray films overnight.

\section{mRNA Isolation and First Strand cDNA Synthesis}

Total RNA from different tissues was prepared using the guanidinium isothiocyanate method followed by cesium chloride centrifugation (Sambrook et al., 1989). Poly(A) ${ }^{+}$RNA from cultured myotubes was isolated by using the Micro-Fast Track mRNA isolation kit (Invitrogen). The amount of RNA isolated was determined by the absorbance at $260 \mathrm{~nm}$. To generate first strand CDNA, $\sim 2 \mu \mathrm{g}$ of total RNA or $\sim 0.2 \mu \mathrm{g}$ of poly $(\mathrm{A})^{+} \mathrm{RNA}$ was reverse transcribed for $1 \mathrm{hr}$ at $37^{\circ} \mathrm{C}$ with $200 \mathrm{U}$ of Moloney's murine leukemia virus reverse transcriptase (BRL) in the presence of $1 \mu \mathrm{M}$ random primers (Pharmacia), $0.6 \mathrm{mM}$ dNTPs, and $40 \mathrm{U}$ of RNAase inhibitor (RNAguard, Pharmacia). Enzymes were inactivated by heating the reaction mixture to $95^{\circ} \mathrm{C}$ for $5 \mathrm{~min}$. Samples were stored at $-70^{\circ} \mathrm{C}$.

\section{Polymerase Chain Reactions}

PCR on first strand CDNA with different pairs of specific primers was done as follows: Ten microliters of the cDNA reaction mix was used, and reaction conditions were adjusted to $10 \mathrm{mM}$ Tris$\mathrm{HCl}$ (pH 8.3), $50 \mathrm{mM} \mathrm{KCl}, 1.5 \mathrm{mM} \mathrm{MgCl}, 0.2 \mathrm{mM}$ dNTPs, $30 \mathrm{pmol}$ of each specific primer, $50 \mu \mathrm{Ci} / \mathrm{ml}\left[\alpha_{-}^{32} \mathrm{P}\right] \mathrm{dCTP}$, and $2.5 \mathrm{U}$ of Taq polymerase. DNA was amplified in a thermal cycler (Perkin Elmer Cetus) using $25 \mathrm{cycles}\left(94^{\circ} \mathrm{C}\right.$ for $1 \mathrm{~min}, 55^{\circ} \mathrm{C}$ for $2 \mathrm{~min}, 72^{\circ} \mathrm{C}$ for $2 \mathrm{~min}$ ). For reamplifications, DNA products from the first round were diluted 1:1000, and PCR was performed using 20 cycles. To amplify genomic sequences that contain regions $A$ and $B, 1 \mu g$ of chick genomic DNA was subjected to PCR using different synthetic oligonucleotides deduced from the nucleotide sequence of $\mathrm{CBA}-1$. After purification from agarose gels, the products were subcloned into PCR 1000 cloning vector (Invitrogen) and sequenced using oligonucleotides deduced from CBA-1. In all the gels shown, $10-30 \mu$ l of the PCR reactions was electrophoresed on an $8 \%$ or $10 \%$ Tris-borate, EDTA polyacrylamide gel (Sambrook et al., 1989) and autoradiographed.

\section{Oligonucleotides}

Synthetic oligonucleotides used in PCR experiments (see Figure $4 \mathrm{~B}$ for their location) were as follows:

1s, 5'-CAACACCTGGATAAGCG; 2s, 5'-ACAATGGCGACAGGGTGATG; 3s, 5'-TTGATGGTAGGACGTACAT; 1a, 5'-GTAGAATGGCTCCTTCAGGT; 2a, 5'-CAGGGTAGTCCAATGCGTCG; 3a, 5'-CTTCTGIITGATGCTCAGCTC.

\section{Acknowledgments}

We thank Dr. Bruce G. Wallace (University of Colorado School of Medicine) for critical comments on the manuscript, Dr. William R. Randall (University of Maryland School of Medicine) for providing us with the chick muscle library, and Robert M. Marshall and Yiran Wang-Zhu for excellent technical assistance. This research was supported by postdoctoral fellowships from the Swiss National Science Foundation (M. A. R. and G. E.), the Schweizerische Stiftung für medizinisch-biologische Stipendien (M. A. R.), the Muscular Dystrophy Association of America (K. W. K. T.), and the Deutsche Forschungsgemeinschaft (S. K.), by an APAMFP predoctoral fellowship (S. E. H.), by grants from the National Institutes of Health, the Muscular Dystrophy Association of America, and the McKnight Foundation (U. J. M.), and by gifts from Mr. Keith and Mrs. Alice Linden and Mr. Robert Sackman.

The costs of publication of this article were defrayed in part by the payment of page charges. This article must therefore be hereby marked "advertisement" in accordance with 18 USC Section 1734 solely to indicate this fact.

Received January 8, 1992; revised February 26, 1992.

\section{References}

Bonner, W. M., and Laskey, R. A. (1974). A film detection method for tritium-labelled proteins and nucleic acids in polyacrylamide gels. Eur. J. Biochem. 46, 83-88.

Burden, S. J., Sargent, P. B., and McMahan, U. J. (1979). Acetylcholine receptors in regenerating muscle accumulate at original synaptic sites in the absence of nerve. J. Cell Biol. 82, 412-425.

Campanelli, J. T., Hoch, W., Rupp, F., Kreiner, T., and Scheller, R. H. (1991). Agrin mediates cell contact-induced acetylcholine receptor clustering. Cell 67, 909-916.

Elliott, J. F., Albrecht, G. R., Gilladoga, A., Handunnetti, S. M., Neequaye, J., Lallinger, G., Minjas, J. N., and Howard, R. J. (1990). Genes for Plasmodium falciparum surface antigens cloned by expression in COS cells. Proc. Natl. Acad. Sci. USA 87, 6363-6367.

Fallon, J. R., and Gelfman, C. E. (1989). Agrin-related molecules are concentrated at acetylcholine receptor clusters in normal and aneural developing muscle. J. Cell Biol. 108, 1527-1535.

Fehon, R. G., Kooh, P. J., Rebay, I., Regan, C. L., Xu, T., Muskavitch, M. A. T., and Artavanis-Tsakonas, S. (1990). Molecular interactions between the protein product of the neurogenic loci Notch and Delta, two EGF-homologous genes in Drosophila. Cell 61, 523-534.

Feinberg, A. P., and Vogelstein, B. (1983). A technique for radiola- 
beling DNA restriction endonuclease fragments to high specific activity. Anal. Biochem. 132, 6-13.

Godfrey, E. W. (1991). Comparison of agrin-like proteins from the extracellular matrix of chicken kidney and muscle with neural agrin, a synapse organizing protein. Exp. Cell Res. 195, 99-109. Godfrey, E. W., Nitkin, R. M., Wallace, B. G., Rubin, L. L., and MCMahan, U. J. (1984). Components of Torpedo electric organ and muscle that cause aggregation of acetylcholine receptors on cultured muscle cells. J. Cell Biol. 99, 615-627.

Godfrey, E. W., Dietz, M. E., Morstad, A. L., Wallskog, P. A., and Yorde, D. E. (1988a). Acetylcholine receptor-aggregating proteins are associated with the extracellular matrix of many tissues in Torpedo. J. Cell Biol. 106, 1263-1272.

Godfrey, E. W., Siebenlist, R. E., Wallskog, P. A., Walters, L. M., Bolender, D. L., and Yorde, D. E. (1988b). Basal lamina components are concentrated in premuscle masses and at early acetylcholine receptor clusters in chick embryo hindlimb muscles. Dev. Biol. 130, 471-486.

Knaack, D., Shen, I., Salpeter, M. M., and Podleski, T. R. (1986) Selective effects of ascorbic acid on acetylcholine receptors number and distribution. J. Cell Biol. 102, 795-802.

Laemmli, U. K. (1970). Cleavage of structural proteins during the assembly of the head of bacteriophage T4. Nature 227, 680-685. Luthman, H., and Magnusson, G. (1983). High efficiency polyoma DNA transfection of chloroquine treated cells. Nucl. Acids Res. 11, 1295-1308.

Magill-Solc, C., and McMahan, U. J. (1988). Motor neurons contain agrin-like molecules. J. Cell Biol. 107, 1825-1833.

McMahan, U. J. (1990). The agrin hypothesis. Cold Spring Harbor Symp. Quant. Biol. 50, 407-418.

McMahan, U. J., and Slater, C. R. (1984). The influence of basa lamina on the accumulation of acetylcholine receptors at synaptic sites in regenerating muscle. J. Cell Biol. 98, 1453-1473.

Nastuk, M. A., Lieth, E., Ma, J., Cardasis, C. A., Moynihan, E. B., McKechnie, B. A., and Fallon, J. R. (1991). The putative agrin receptor binds ligand in a calcium-dependent manner and aggregates during agrin-induced acetylcholine receptor clustering. Neuron 7, 807-818.

New, H. V., and Mudge, A. W. (1986). Calcitonin gene-related peptide regulates muscle acetylcholine receptor synthesis. Nature 323, 809-811.

Nitkin, R. M., Smith, M. A., Magill, C., Fallon, J. R., Yao, Y.-M. M., Wallace, B. G., and MCMahan, U. J. (1987). Identification of agrin, a synaptic organizing protein from Torpedo electric organ. J. Cell Biol. 105, 2471-2478.

Oh, T. H., and Markelonis, G. I. (1982). Chicken serum transferrin duplicates the myotrophic effects of sciatin on cultured muscle cells. J. Neurosci. Res. 8, 535-545.

Padgett, R. A., Grabowski, P. J., Konarska, M. M., Seiler, S., and Sharp, P. A. (1986). Splicing of messenger RNA precursors. Annu. Rev. Biochem. 55, 1119-1150.

Peng, H. B., Cheng, P.-C., and Luther, P. W. (1981). Formation of ACh receptor clusters induced by positively charged Latex beads. Nature 292, 831-834.

Ranscht, B. (1988). Sequence of contactin, a 130-kD glycoprotein concentrated in areas of interneuronal contact, defines a new member of the immunoglobulin supergene family in the nervous system. J. Cell Biol. 107, 1561-1573.

Rebay, I., Fleming, R. J., Fehon, R. G., Cherbas, L., Cherbas, P., and Artavanis-Tsakonas, S. (1991). Specific EGF repeats of notch mediate interactions with delta and serrate: implications for notch as a multifunctional receptor. Cell 67, 687-699.

Reist, N. E., Magill, C., and MCMahan, U. J. (1987). Agrin-like molecules at synaptic sites in normal, denervated, and damaged skeletal muscles. J. Cell Biol. 105, 2457-2469.

Reist, N. E., Werle, M. J., and McMahan, U. J. (1992). Agrin released by motor neurons induces the aggregation of acetylcholine receptors at neuromuscular junctions. Neuron, in press.
Rupp, F., Payan, D. G., Magill-Solc, C., Cowan, D. M., and Scheller, R. H. (1991). Structure and expression of a rat agrin. Neuron 6, 811-823.

Sambrook, J. M., Fritsch, E. F., and Maniatis, T. (1989). Molecular Cloning: A Laboratory Manual, Second Edition (Cold Spring Harbor, New York: Cold Spring Harbor Laboratory).

Sanger, F., Nicklen, S., and Coulson, A. R. (1977). DNA sequencing with chain-terminating inhibitors. Proc. Natl. Acad. Sci. USA $74,5463-5467$.

Tabor, S., and Richardson, C. C. (1985). A bacteriophage T7 RNA polymerase/promoter system for controlled exclusive expression of specific genes. Proc. Natl. Acad. Sci. USA 82, 1074-1078.

Tsim, K. W. K., Ruegg, M. A., Escher, G., Kröger, S., and McMahan, U. J. (1992). cDNA that encodes active agrin. Neuron, this issue.

Usdin, T. B., and Fischbach, G. D. (1986). Purification and characterization of a polypeptide from chick brain that promotes the accumulation of acetylcholine receptors in chick myotubes. I. Cell Biol. 103, 493-507.

Vogel, Z., Christian, C. N., Vigny, M., Bauer, H. C., Sonderegger, P., and Daniels, M. P. (1983). Laminin induces acetylcholine receptor aggregation on cultured myotubes and enhances the receptor aggregation activity of a neuronal factor. J. Neurosci. 3, 1058-1068.

Wallace, B. G. (1986). Aggregating factor from Torpedo electric organ induces patches containing acetylcholine receptors, ace tylcholinesterase and butyrylcholinesterase on cultured myotubes. J. Cell Biol. 102, 783-794.

Wallace, B. G., Nitkin, R. M., Reist, N. E., Fallon, J. R., Moayeri, N. N., and McMahan, U. J. (1985). Aggregates of acetylcholinesterase induced by acetylcholine receptor-aggregating factor. $\mathrm{Na}$ ture 315, 574-577.

Wallace, B. G., Qu, Z., and Huganir, R. L. (1991). Agrin induces phosphorylation of the nicotinic acetyicholine receptor. Neuron $6,869-878$. 